\title{
An Update on Bioactive Glass in Bone Tissue Engineering
} Toosi S and Behravan $\mathrm{J}^{*}$

Biotechnology Research Center, Mashhad University of Medical Sciences, Mashhad, Iran

\section{Editorial}

Tissue engineering focuses on combining engineering technology and biological science so as to regenerate and repair lost or damaged tissue. The most widely used method involves using biomaterial scaffold with a well-defined architecture that acts as a temporary structure for the cells, which guides their proliferation and differentiation into the targeted tissue or organ. The incorporation of growth factors and some other biomolecules into the scaffold with the cells can guide the regulation of cellular functions during tissue or organ regeneration [1]. Bioactive material refers to material that can induce certain biological activity [2]. To be more specific, a bioactive material is a material that experiences certain surface reactions as it is inserted into the body, causing a hydroxyapatite (HA) -like layer to form, which is liable for strong bonding with hard and soft tissues [3]. The material's capacity to form an HA-like surface layer while submerged in a simulated body fluid (SBF) in vitro indicates the bioactivity of the material. From the time of discovering $45 \mathrm{~S} 5$ bioactive glasses, scientists have commonly regarded them as suitable scaffold materials for bone repair. Bioactive glasses are thought of mostly as capable of encouraging the growth of bone cells and to bond firmly with hard and soft tissue. Upon implantation, bioactive glasses experience certain reactions that cause an amorphous calcium phosphate (ACP) or crystalline HA phase to develop on the surface of the glass, which is why they bind firmly to the nearby tissue. Moreover, bioactive glasses can release ions that initiate osteogenic gene expression and excite angiogenesis and they can bond to bone quicker than other bioactive ceramics [4] and excite human osteoblast cells at the genetic level. This activity has been ascribed to soluble silica and calcium ions as they are freed from the glasses following implantation. The biological activity of synthetic HA is also enhanced through the process of substitution (chemical) of silicon (silicate groups) for phosphorous (phosphate groups) [5], which has caused the production of the successful clinical product, Actifuse (Apatech Ltd, UK). We know that biologically active glass scaffolds with compressive strengths are comparable to those of trabecular bone, which have been produced, and these scaffolds can potentially repair non-loaded bone defects. Recently, bioactive glass scaffolds with similar strengths to cortical bone have been produced, and these scaffolds can potentially repair loaded bone defects. The durability and mechanical reliability of bioactive glass scaffolds are factors that limit the applications in loaded bone repair; however, their capabilities have been ignored. Inclusion of a biocompatible polymer coating has been suggested to enhance the durability of bioactive glass scaffolds; thus, allowing a crack bridging mechanism by the polymer layer for energy dissipation. Future investigations should concentrate on producing durable and strong bioactive glass scaffolds via innovative fabrication methods. Moreover, these scaffolds should be evaluated in loaded and non-loaded bone defect sites in animal models.

\section{References}

1. Bellucci D, Sola B, Cannillo V (2016) Hydroxyapatite and tricalcium phosphate composites with bioactive glass as second phase: State of the art and current applications. J Biomed Mater Res A 104: 1030-1056.

2. Chen FM, Liu X (2016) Advancing biomaterials of human origin for tissue engineering. Prog Polym Sci 53: 86-168

3. Denry I, Kuhn LT (2016) Design and characterization of calcium phosphate ceramic scaffolds for bone tissue engineering. Dent Mater 32: 43-53.

4. Ocampo JIG, Sierra DME, Orozco CPO (2016) Porous bodies of hydroxyapatite produced by a combination of the gel-casting and polymer sponge methods. JAR 7: 297-304.

5. Webber M.J, Appel EA, Meijer EW, Langer R (2016) Supramolecular biomaterials. Nat Mater 15: 13.
*Corresponding author: Javad Behravan, Biotechnology Research Center, Mashhad University of Medical Sciences, Mashhad, Iran, Tel: +985138823255 E-mail: E-mail: Behravanj@mums.ac.ir

Received September 26, 2017; Accepted September 27, 2017; Published October 06, 2017

Citation: Toosi S, Behravan J (2017) An Update on Bioactive Glass in Bone Tissue Engineering. Bioceram Dev Appl 7: e111. doi: 10.4172/2090-5025.1000e111

Copyright: (๑) 2017 Toosi S, et al. This is an open-access article distributed under the terms of the Creative Commons Attribution License, which permits unrestricted use, distribution, and reproduction in any medium, provided the original author and source are credited. 